\title{
Spontaneous Bilateral Tubal Ectopic Pregnancy: A Case Report
}

\author{
Lhagadang Foumsou1,2*, Bray Madoué Gabkika1,2, Damthéou Sadjoli1,2, Bray Madoué Kaïmba3 \\ ${ }^{1}$ Department of Gynaecology and Obstetrics, Faculty of Human Health Sciences, University of N’Djamena, N’Djamena, Chad \\ ${ }^{2}$ N'Djamena Mother and Child Hospital, N’Djamena, Chad \\ ${ }^{3}$ Department of Surgery, Faculty of Human Health Sciences, University of N'Djamena, N'Djamena, Chad \\ Email: ^faribasepahvand@yahoo.com
}

How to cite this paper: Foumsou, L., Gabkika, B.M., Sadjoli, D. and Kaïmba, B.M. (2017) Spontaneous Bilateral Tubal Ectopic Pregnancy: A Case Report. Open Journal of Obstetrics and Gynecology, 7, 866-870. https://doi.org/10.4236/ojog.2017.78087

Received: October 25, 2016

Accepted: July 31, 2017

Published: August 3, 2017

Copyright (c) 2017 by authors and Scientific Research Publishing Inc. This work is licensed under the Creative Commons Attribution International License (CC BY 4.0).

http://creativecommons.org/licenses/by/4.0/

\begin{abstract}
Bilateral ectopic pregnancy is the rarest form of ectopic pregnancy. We report a case of spontaneous bilateral tubal ectopic pregnancy diagnosed intra operatively. A 30-year-old patient was admitted to the emergency room of N'Djamena mother and child hospital complaining of vaginal bleeding and abdominal pain. Salpingectomy left tube and salpingotomy right tube were performed without complication and that histopathological report confirmed the diagnosis.
\end{abstract}

\section{Keywords}

Bilateral Ectopic Pregnancy, Salpingectomy, Salpingotomy

\section{Introduction}

Bilateral tubal pregnancy in the absence of preceding induction of ovulation is an extremely unusual occurrence [1] [2]. In the medical literature, there are approximately 250 cases reported. The true incidence of ectopic bilateral pregnancy is unknown [3]. It is estimated, however, to be between 1 in 750 and 1580 ectopic pregnancies and 1 in 200,000 live births [3] [4] [5]. We report an unusual case of ectopic pregnancy in which patient had spontaneous bilateral tubal ectopic pregnancy discovered during an emergency laparotomy. The histopathological examination confirms the bilateral tubal pregnancy.

\section{Case Report}

A 30-year old woman Chadian was admitted in the emergency room of N'Djamena mother and child hospital with complaints of vaginal bleeding and abdominal pain. Her last menses was seven weeks before the visit and she had positive pregnancy test after missing her monthly menstrual period. She was nullipar- 
ous, sexually active and had history of pelvis inflammatory disease, no prior intra uterine contraceptive device, no use of fertility drugs and tubal surgery. There was no history of ovulation stimulation or assisted reproductive techniques.

On examination, there was moderate degree of pallor with tachycardia. Her vital sign was normal except the tachycardia (heart rate of 95 - 110 beats/minute). There was diffuse abdominal tenderness but no guarding or rigidity. Her vulva was blood-stained, there was active bleeding through the cervical bone. Vaginal examination revealed a normal sized uterus, with fullness in the Pouch of Douglas (POD) and a tender mass in the right fornix.

Pelvic ultrasound scan revealed an empty uterus, a right adnexal mass of size $5.6 \times 3.8 \mathrm{c}$, in the POD and an important amount of collection in the pelvis suggestive of blood. The hematocrit was $21.2 \%$ and hemoglobin $7.2 \mathrm{~g} / \mathrm{dl}$.

The finding led to a diagnosis of ruptured tubal pregnancy and the patient was counseled on the need for immediate surgical intervention and she consented. At laparotomy, there was $700 \mathrm{ml}$ of haemoperitoneum with approximately $300 \mathrm{ml}$ of clot in the POD. The left tube was the seat of tubal rupture ectopic pregnancy in the ampullary region. The uterus was normal in size. On inspection of the right tube, there was another mass of $4 \times 3 \mathrm{~cm}$ in the ampullary region with a thinned out bulging point suggestive of near rupture. The ovaries were normal.

Salpingectomy left tube and salpingotomy right were performed and product of conception from both tubes were sent for histopathological examination, which later confirmed the presence of chorionic villi in both tubes. A single dose of methotrexate was given followed by the hCG monitoring. Her postoperative period was enlarged and uneventful, and she was discharged on day 7 in stable condition. The initial value of hCG was $12,997.4 \mathrm{UI} / \mathrm{L}$ that fallen to 5 $\mathrm{UI} / \mathrm{L}$ on the $30^{\text {th }}$ day after the methotrexate dose. Anemia was managed with oral dose of $120 \mathrm{mg}$ per day of iron (for a month). The evaluation done a month after revealed the hematocrit rate of $30.7 \%$ (hemoglobin $10.2 \mathrm{~g} / \mathrm{dl}$ ) (Figures $1-3)$.

\section{Discussion}

Bilateral tubal ectopic pregnancies are a rare gynecological condition with great potential for causing maternal mortality and morbidity. Despite the rarity of the

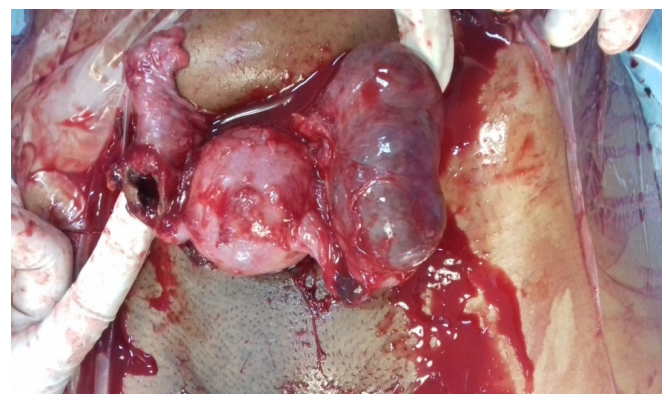

Figure 1. Bilateral tubal ectopic pregnancy (credit Bray). 


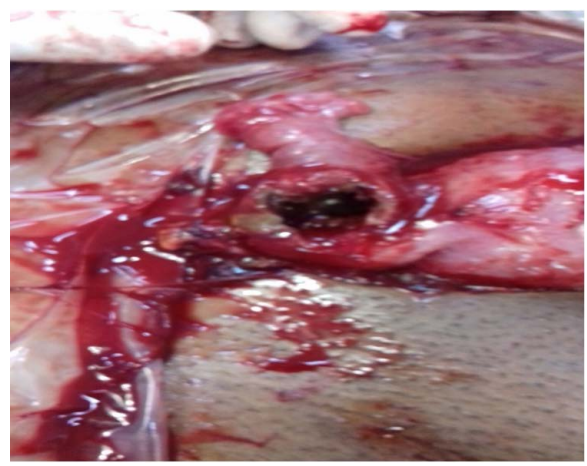

Figure 2. Left ruptured tubal pregnancy (credit Bray).

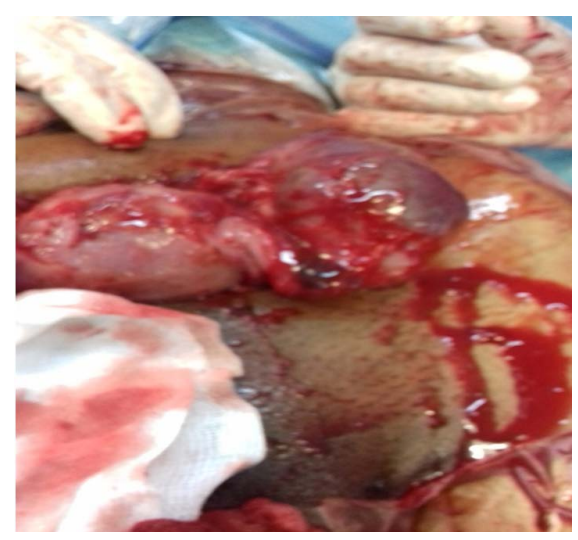

Figure 3. Right unruptured tubal pregnancy (credit Bray).

BEP, it must be entertained in the differential diagnosis because the consequences of missing it are likely to be catastrophic [3]. Its true incidence is not known, but because it has been reported with increasing frequency in a recent time, may be on the increase [6]. Higher incidence of BTP has been seen after the use of Assisted Reproductive Techniques (ARTs) or following ovulation induction [7].

Risk factors include the presence of predisposing factors to the ectopic pregnancy. In our case, the history of pelvis inflammatory disease can be cited as predisposing factors. In a recent survey, Gabkika [8] and Foumsou [9] had reported infection like main risk factor of ectopic pregnancy in Chad. The clinical presentation of BEP is unpredictable. It bears no unique clinical feature to distinguish it from unilateral ectopic pregnancy. The literature and clinical findings regarding diagnosis of bilateral ectopic pregnancy are not comprehensive. In our case, the classic triad of pain vaginal bleeding and missed period was present to unilateral ectopic pregnancy. As the diagnose of an ectopic pregnancy often rests on an absence of an intra-uterine pregnancy rather than direct visualization of the ectopic itself, ultrasonography cannot relied upon to make the diagnosis of BEP [3]. Spontaneous bilateral ectopic pregnancy is rare; therefore, preoperative diagnosis is uncommon indicating limitations of ultrasonography [10]. In our case, also, preoperative ultrasound failed to diagnose bilateral tubal ectopic pregnancy. The most common way of diagnosing the bilateral ectopic pregnancy is the direct examination of both tubes during laparotomy or surgical laparos- 
copy. Based on intra operative findings, most of patients had ampullary ectopic pregnancy. Bilateral rupture of tubes was rare. In 5 out of 19 cases in a review of secondary bilateral ectopic pregnancy, unilateral tubal rupture in operative field was demonstrated. None of case was bilaterally ruptured [11]. In our case, unilateral rupture tubal pregnancy (in the left) in ampullary portion of tube and another unruptured tubal pregnancy (in the right) were seen. Our patient had the right tube distended about $4 \mathrm{~cm}$.

Comprehensive clinical guidelines for the treatment of ectopic pregnancy have been published by Royal College of Obstetricians and Gynecologist [12]. Because of its rarity, synchronous ectopic pregnancy is not covered, but principles of treatment can still be applied. Thus the management of the bilateral tubal ectopic pregnancy may be medical or surgical, and depend to the large extend on the state of the fallopian tubes at presentation. The main challenge being to identify and treat as early as possible those cases of ectopic pregnancy with the potential to cause serious morbidity or death. Medical management was not suitable in our case because the patient had developed a pelvic hematoma with contra-indicated medical treatment. In developed country, laparoscopy surgical treatment is preferred to open procedure because the patient recovers more quickly and subsequent rate of intra uterine and ectopic pregnancy are similar. A woman with hemodynamic instability due intraperitoneal haemorrhage should be treated by the most expedient surgical method to gain rapid haemostasis. Without evidence for an open laparoscopic approach for women in shock, laparotomy has traditionally been favored [12]. More evidences suggested that laparoscopic treatment is safe and effective for suitable trained and experienced staff [12] [13].

The implementation of laparoscopic procedure in developing country like ours is difficult because of poverty or absence of adequate material [8] [9]. In such area, laparotomy remains the only surgical appraoch. Then, emergency laparotomy was performed. There are three surgical approaches for ectopic pregnancy: salpingectomy, salpingostomy and radical salpingectomy. Despite our limited experience, we performed left salpingectomy and right salpingotomy this was mainly to leave our patient with the hope of future fertility and so prevents the family disintegration associated with childlessness. The use of methotrexate and hCG monitoring in our case can be explained by the fact that the salpingotomy has a great risk of persistent trophoblastic activity. Prior studied had shown the methotrexate as appropriate treatment of persistent trophoblastic activity [12] [13].

The counseling in our case is important. For better management this patient was advised to go to ARTs that remains the best reproductive way.

\section{Conclusion}

Bilateral tubal pregnancy in the absence of preceding induction of ovulation is an extremely unusual occurrence. The clinical presentation of BEP is unpredictable. The most common way of diagnosing the bilateral ectopic pregnancy is the 
direct examination of both tubes during laparotomy or laparoscopy. In developing country like Chad, laparotomy remains the only way for surgical approach. Regarding the plan of fertility procedures, conservation or resection of fallopian tubes might planned in the operation field looking before on the social problem caused the childlessness.

\section{References}

[1] Arab, M., Kazemi, S.N., Vahedpoorfard, Z. and Ashoori, A. (2015) A Rare Case of Bilateral Ectopic Pregnancy and Differential Diagnosis of Gestational Trophoblastic Disease. Journal of Reproduction \& Infertility, 16, 49-52.

[2] Oron, G. and Tulandi, T.A (2013) Pragmatic and Evidence-Based Management of Ectopic Pregnancy. Journal of Minimally Invasive Gynecology, 20, 446-454. https://doi.org/10.1016/j.jmig.2013.02.004

[3] Lobo, R.A., Patrício, L., Milheiras E., et al. (2012) Bilateral Tubal Ectopic Pregancy. Acta Obstet Ginecol Port, 6, 141-144.

[4] Greenberg, J.A. (2008) Bilateral Ectopic Pregnancy. Reviews in Obstetrics \& Gynecology, $1,48-51$.

[5] De Los Rios, J.F., Castaneda, J.D. and Miryam, A. (2007) Bilateral Ectopic Pregnancy. Journal of Minimally Invasive Gynecology, 14, 419-427. https://doi.org/10.1016/j.jmig.2007.01.011

[6] Andrews, J. and Farrell, S. (2008) Spontaneous Bilateral Tubal Pregnancies: A Case Report. Journal of Obstetrics and Gynaecology Canada, 30, 51-54. https://doi.org/10.1016/S1701-2163(16)32713-X

[7] Brady, J. and Wilson, M. (2005) Spontaneous Bilateral Tubal Ectopic Pregnancy. Journal of the Royal Society of Medicine, 98, 120-121. https://doi.org/10.1258/jrsm.98.3.120

[8] Gabkika, B.M., Abdelsalam, S., Ilboudo, S.R., et al. (2015) Ectopic Pregnancy: Epidemiological Aspect and Maternal Prognose at N’Djamena South District Hospital (Chad). Kisangani Médical, 6, 111-116.

[9] Foumsou, L., Choua, O., Djimtessem, O., et al. (2014) Epidemiological Aspect and Prognosis of Ectopic Pregnancy at N'Djamena Mother and Child Hospital. Annales de la Soggo, 22, 34-38.

[10] Amine, B.H.H. and Haythem, S. (2015) Extra-Uterine Twin Pregnancy: Case Report of Spontaneous Bilateral Tubal Ectopic Pregnancy. Pan African Medical Journal, 20, 435.

[11] Rani, V.R.S. and Puliyath, G. (2013) Viable Intrauterine Pregnancy after Spontaneous Bilateral Tubal Ectopics in a Multiparous Woman: A Case Report. Journal of Medical Case Reports, 7, 159. https://doi.org/10.1186/1752-1947-7-159

[12] Kelly, A.J., Sowter, M.C. and Trinder, J. (2004) The Management of Tubal Pregnancy. RCOG Press, London.

[13] Odejinmi, F., Sangrithi, M. and Olowu, O. (2011) Operative Laparoscopy as the Main Stay Method in Management of Hemodynamically Unstable Patients with Ectopic Pregnancy. Journal Minimal Invasive Gynecology, 18, 179-183. https://doi.org/10.1016/j.jmig.2010.11.005 
Submit or recommend next manuscript to SCIRP and we will provide best service for you:

Accepting pre-submission inquiries through Email, Facebook, LinkedIn, Twitter, etc. A wide selection of journals (inclusive of 9 subjects, more than 200 journals)

Providing 24-hour high-quality service

User-friendly online submission system

Fair and swift peer-review system

Efficient typesetting and proofreading procedure

Display of the result of downloads and visits, as well as the number of cited articles Maximum dissemination of your research work

Submit your manuscript at: http://papersubmission.scirp.org/

Or contact ojog@scirp.org 